\title{
Effects of Sexual Dysfunction on Female Teachers Performance
}

\author{
M. Kanedi ${ }^{1, *}$, Sutyarso ${ }^{2}$ \\ ${ }^{1}$ Department of Biology, Faculty of Mathematics and Sciences, University of Lampung, Indonesia \\ ${ }^{2}$ Department of Biomedical Sciences, Faculty of Medicine, University of Lampung, Indonesia \\ *Corresponding author: wegayendi@yahoo.com
}

Received November 04, 2014; Revised November 27, 2014; Accepted December 01, 2014

\begin{abstract}
This research is aimed to find out whether sexual dysfunction affects female teachers performance in fulfilling pedagogical tasks. Eighty-four female teachers who work at 12 elementary schools in the city of Bandar Lampung, Lampung Province, Indonesia became the participants in this study. To assess the teacher's sexual quality, we used the Female Sexual Function Index (FSFI), a brief questionnaire designed to measure sexual functioning in women with focus on sexual desire, sexual arousal, lubrication, orgasm, satisfaction, and pain. To measure the quality of a teacher, two pupils were asked to become respondents and fill out a Likert Scale questionnaire containing both positive and negative quality indicators of the teacher. The positive indicators consist of punctual, prepared, approachable, respectful and professional, while the negative ones include bad tempered, rude, insulting, arrogant and domineering. Mann-Whitney comparison test and Spearman Rank Correlation were performed in data analysis. The results showed that 39 (46\%) of the participant categorized as teachers without sexual disorder (total FSFI score of 29.1 \pm 1.33 ) and the other 45 (54\%) categorized as teachers with sexual disorders (total FSFI score of $21.48 \pm 2.84$ ). Compared with the teacher without sexual dysfunction, teachers with sexual disorders tend to be less diligent $(\mathrm{P}<0.05)$, less prepared for class $(\mathrm{P}<0.001)$, less friendly $(\mathrm{P}<0.001)$ and less appreciative students $(\mathrm{P}$ $<0.01)$. In addition, teachers with sexual problems tend to be more hothead $(\mathrm{P}<0.001)$, rude $(\mathrm{P}<0.001)$ and domineering $(\mathrm{P}<0.01)$. As the conclusion, sexual dysfunction potentially affects teaching performance of the female teachers.
\end{abstract}

Keywords: sexual dysfunction, female teachers, quality of teachers, teacher's behavior

Cite This Article: M. Kanedi, and Sutyarso, "Effects of Sexual Dysfunction on Female Teachers Performance.” American Journal of Public Health Research, vol. 2, no. 6 (2014): 244-247. doi: 10.12691/ajphr-2-6-5.

\section{Introduction}

The studies of female sexual dysfunction in the past two decades have been so intense and give effect to the abundance of literature on the prevalence, causes, symptoms, classification and treatment of sexual disorders in women. However, most studies are based on and intended for the benefit of women themselves. [1]. In contrast, the studies of the relationship between sexual dysfunction in women with their socio-economic functions are still very limited. As a result, both the direct and indirect influence of the sexual disorder of women on their professional productivity is unknown. In fact, the socio-economic role of women in many countries around the world, including Indonesia, has increased significantly [2].

One of the formal professions favored by women in many parts of the world is teacher. In 1995 there was at least 28.7 million of women work as teachers at the preschools, elementary schools, and middle schools all over the world [3]. The global data of the year 2010 showed that teacher profession at schools of all levels still dominated by women [4]. In Indonesia alone, the percentage of female teachers at the pre-schools, elementary schools, and middle schools is more than $60 \%$ [5].

The high number of women involved in teacher profession imply that women have a major role in the initial process of the character building of a nation. However, to build human character is not an easy process for everyone. That's why prospective teachers should meet the requirements including knowledgeable, capable, integrity, healthy physically and mentally [6]. Mental and physical health allegedly associated with the professional performance of teachers [7]. Moreover, the physical and mental health it self evidently related to sexual health [8].

In educational world, one of the factors known to affect the effectiveness of teaching is teacher quality itself. A qualified teacher is a teacher that able to show behaviors that encourage, instead of hamper, the learning process of the pupils [9]. Therefore, teachers should be able to keep their own emotional stability in dealing with the diversity of the pupil doings. The failure of teachers in maintaining emotional stability may give rise to fear on pupils. Fear might cause the motivation in learning diminished [10].

The best way to assess quality of teachers is by taking the testimony of their own pupils $[11,12]$. There are at least 28 quality indicators of a teacher that can be rated by student based on the teacher's observable behaviors [13]. 
If sexual disorders can affect physical and mental health, while physical and mental health affects one's professional performance, then the sexual disorders in women also definitely would affect the effectiveness of their work. Our previous study, in the city of Bandar Lampung, revealed that the prevalence of female teachers suffered from sexual dysfunction can be categorized as high. Thus, current study is a follow-up study to investigate the consequence that may arise from such sexual dysfunction.

\section{Materials and Methods}

\subsection{The Participant}

From July to September 2012 we have been investigating the quality of the sexual function of 84 female teachers working in 12 primary schools in the city of Bandar Lampung, Indonesia. They were the teachers of grade 4,5 , and 6 . To re-check the sexual function of these teachers and evaluating its effects on the pedagogical performance, they were re-invited to participate in current study. To asses the quality of teachers, two of disciples of each teacher, one male and one female, were chosen randomly and asked to be respondents. Given the number of teachers involved was 84 then the number of pupils who became the respondents was 168 .

\subsection{Evaluation of Teacher's Sexual Function}

To measure sexual function of female teachers, we use the Female Sexual Function Index (FSFI) - a multidimensional self report instrument — introduced by [14]. To characterize whether a participant suffer from sexual disorder or not, we use criteria suggested by [15], that the FSFI total score of 26.55 is the optimal cut-off score for differentiating women with and without sexual dysfunction.

\subsection{Evaluation of Teacher Quality}

Table 1. Questionnaire designed to pupils in assessing teacher's quality

Teacher's Name: ...

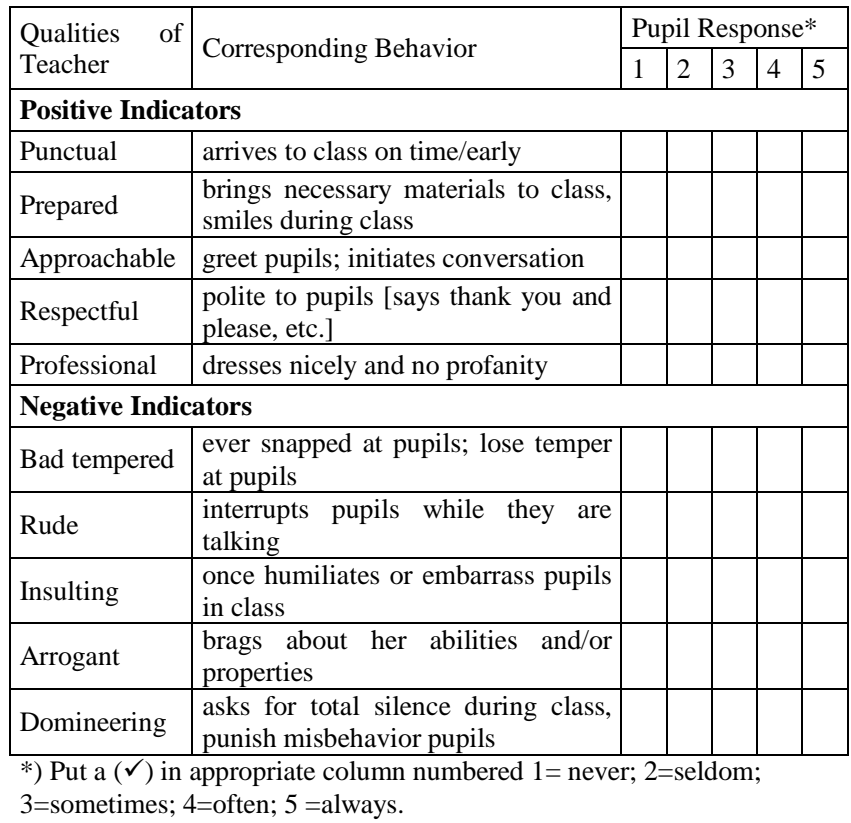

Teacher quality was assessed based on the behavior that corresponds to the quality indicators by asking pupils to do the assessment. Two pupils of each teacher, one male and one female, chosen at random, were asked to fill out a Likert-type questionnaire. The questionnaire, adapted from [13], contains both positive and negative indicators of the teacher quality. The positive indicators include punctual, prepared, approachable, respectful, and professional, while the negative ones include bad tempered, rude, insulting, arrogant, and domineering (Table 1).

\subsection{Statistical Analysis}

Teachers with the FSFI total score of more than 26.5 categorized as the normal group and those of with the total score of less than 26.5 as the group of with sexual disorder. To determine whether there was a statistical difference in behavior between groups, the Mann-Whitney test applied. To see whether there was a relationship between sexual function of the teachers with their quality parameters the Spearman Rank Correlation test has been used.

\section{Results}

\subsection{The Participant Characteristics}

Characteristics of female teachers that participated in this study can be described as follows. Their age ranges from 24 to 59 years with an average of 46.56. The majority of them were married $(85.71 \%)$, have three or more children (64.28\%), lived in owned home (86,9\%), never use any kind of drugs (96.43\%), high education (73.28\%), do not use any contraceptives (61.9\%) and claimed of having sexual activities of four or more times a month $(55.9 \%)$. From the total of 84 participants, 39 of them (46\%) categorized as teachers without sexual disorder (total FSFI score of 29.1 \pm 1.33 ), while the other 45 (54\%) categorized as teachers with sexual disorders (total FSFI score of $21.48 \pm 2.84$ ).

\subsection{The Quality of Teachers and Sexual Problems}

Table 2. The quality of teachers with sexual disorder compared with that of without sexual disorder

\begin{tabular}{llll}
\hline Variables & $\begin{array}{l}\text { Teachers without } \\
\text { sexual disorder } \\
(\text { Mean } \pm \text { SD) }\end{array}$ & $\begin{array}{l}\text { Teachers with } \\
\text { sexual } \\
\text { disorder } \\
(\text { Mean } \pm \text { SD) }\end{array}$ & $\begin{array}{l}\text { Level of } \\
\text { significant }\end{array}$ \\
\hline $\begin{array}{l}\text { Positive Behavior } \\
\text { (Mean score) }\end{array}$ & $4.30 \pm 0.38$ & $3.88 \pm 0.45$ & $* * *$ \\
Punctual & $4.37 \pm 0.48$ & $4.06 \pm 0.57$ & $*$ \\
Prepared & $4.23 \pm 0.68$ & $3.42 \pm 0.55$ & $* * *$ \\
Approachable & $4.17 \pm 0.60$ & $3.69 \pm 0.65$ & $* * *$ \\
Respectful & $4.12 \pm 0.67$ & $3.68 \pm 0.65$ & $* *$ \\
Professional & $4.63 \pm 0.38$ & $4.54 \pm 0.46$ & \\
Negative Behavior & $1.66 \pm 0.27$ & $1.99 \pm 0.28$ & $* * *$ \\
(Mean score) & $1.62 \pm 0.47$ & $2.23 \pm 0.46$ & $* * *$ \\
Bad-Tempered & $1.83 \pm 0.50$ & $2.40 \pm 0.58$ & $* * *$ \\
Rude & $1.32 \pm 0.41$ & $1.41 \pm 0.36$ & \\
Insulting & $1.51 \pm 0.56$ & $1.53 \pm 0.44$ & $* *$ \\
Arrogant & $2.04 \pm 0.57$ & $2.36 \pm 0.45$ & $* *$ \\
Domineering & &
\end{tabular}

Mann-Whitney Test: $*=\mathrm{P}<0.05 ; * *=\mathrm{P}<0.01 ; * * *=\mathrm{P}<0.001$. 
Comparisons of the quality parameters between teachers with and without sexual dysfunction are presented in Table 2. Teachers with sexual dysfunction showed tendency of less punctual, less prepared, less friendly, less respect, more hothead, rude and domineering.

\subsection{Relationship between Quality of Teachers and the FSFI scores}

The Spearman Rank Correlation coefficient ( $\boldsymbol{r}$ ) between sexual function and behavior of the participants are presented in Table 3. Amongst the six domains of sexual function, orgasmic disorder is the most related to the teacher's behavior, while the vaginal pain is the domain that not related to any indicator of the teacher quality. None of sexual problems i.e. lack of desire, arousal disorder, troubled with lubrication, unable to orgasm, low satisfaction, and vaginal pain that associated with the professional and arrogance of a teacher.

Table 3. The Coefficient of Correlation ( $r$ ) of Relationship between Quality of Female Teachers and Their Sexual Function

\begin{tabular}{|c|c|c|c|c|c|c|c|}
\hline & Desire & Arousal & Lubrication & Orgasm & Satisfaction & Pain & $\begin{array}{l}\text { Total F } \\
\text { SFI Score }\end{array}$ \\
\hline \multicolumn{8}{|c|}{ Positive Behavior } \\
\hline Punctual & $0,388 * * *$ & $0,334 * *$ & $0,254 *$ & $0,326 * *$ & 0,009 & $-0,023$ & $0,302 * *$ \\
\hline Prepared & $0,55^{* * *}$ & $0,359 * * *$ & $0,538 * * *$ & $0,489 * * *$ & $-0,035$ & 0,067 & $0,518^{* * *}$ \\
\hline Approachable & $0,424 * * *$ & $0,424^{* * *}$ & $0,391 * * *$ & $0,431^{* * *}$ & 0,066 & 0,005 & $0,41^{* * *}$ \\
\hline Respectful & $0,351^{* *}$ & $0,386 * *$ & $0,344 * *$ & $0,378 * * *$ & 0,048 & 0,089 & $0,361 * *$ \\
\hline Professional & 0,128 & 0,179 & 0,048 & $0,233^{*}$ & 0,137 & 0,04 & 0,14 \\
\hline \multicolumn{8}{|c|}{ Negative Behavior } \\
\hline Bad Tempered & $-0,4^{* * *}$ & $-0,417 * * *$ & $-0,353^{* *}$ & $-0,349 * *$ & $0,248 *$ & $-0,107$ & $-0,43^{* * *}$ \\
\hline Rude & $-0,321 * *$ & $-0,315^{* *}$ & $-0,336 * *$ & $-0,231^{*}$ & $0,367 * *$ & $-0,025$ & $-0,32 * *$ \\
\hline Insulting & $-0,006$ & $-0,002$ & 0,134 & 0,071 & $0,31^{* *}$ & 0,191 & 0,083 \\
\hline Arrogant & 0,116 & 0,064 & $-0,051$ & 0,14 & 0,199 & 0,139 & 0,105 \\
\hline Domineering & $-0,205$ & $-0,219 *$ & $-0,171$ & $-0,313^{* *}$ & $0,345^{* *}$ & 0,065 & $-0,239 *$ \\
\hline
\end{tabular}

Spearman Rank Correlation: $*=\mathrm{P}<0.05 ; * *=\mathrm{P}<0.01 ; * * *=\mathrm{P}<0.001$.

\section{Discussion}

There are three important findings obtained from this study. First, the percentage of participants suffered from sexual disorders was up to $54 \%$. This results can be categorized as high because the prevalence of sexual dysfunction in women in general is about $40 \%$ [16]. But, given the prevalence of sexual dysfunction is changed with age, current results very likely related to the high average age of the participants (46.56 years). In Turkey, as reported by Cayan et al., the prevalence of female suxual dysfunction in the ages of 38-47 years is about 53.5\% [17].

Second, as presented in Table 2, teachers with sexual function scores of less than 26.55 showed tendency of less diligent, less prepared for class, less friendly and lack of respect for the pupils. Moreover, they also become more hothead, impatient and punitive. Such intense behavioral changes is the symptom of emotional or affective instability [18].

Given the sexual dissatisfaction, as experienced by women who subjected to female genital mutilation, as reported by [19], can cause psychological and social disruption, thereby it is likely that the negative behavior exhibited by the teachers with lower FSFI scores associated with sexual problems they experienced. Sexual satisfaction, as revealed by $[20,21]$, also correlated with the quality of life many people of different levels of age including physical and behavioral health.

Third, there is a strong correlation between the total FSFI scores with teacher quality indicators (Table 3). The higher the sexual function of a teacher the higher the tendency of a teacher to display positive behavior. Conversely, the lower the teacher's sexual function the higher the tendency of teachers to behave negatively.

Among the domains of sexual function, orgasm is the only one that associated with mostly teachers quality indicators. The higher the orgasmic function scores the higher the positive behavior scores of the teachers. Furthermore, among the six domains, sexual satisfaction is the only one that is negatively correlated with most of the negative behavior ( 4 of the 5 parameters) of the teachers. The lower the satisfaction function scores the higher the tendency of teacher to become more hotheads, rude, insulting and domineering.

These results confirm the findings of some previous study that one of the sexual function domains that are frequently associated with sexual satisfaction is orgasm. This implies the orgasmic function is an important measure of sexual satisfaction in women [22, 23].

It was also already known that sexual dissatisfaction in women negatively affects general well-being and therefore the sexual satisfaction can be thought as a powerful predictor of psychological well-being [24,25].

In some cases, as presented by Edalati and Redzuan in a review article, sexual and/or marital dissatisfaction are responsible for aggressiveness in women/wife. Women that dissatisfied with their marital were more likely to use physical aggression [26].

We realize that even though the correlation between sexual function scores with the teacher quality parameters can be categorized as strong, this fact does not necessarily indicate a causal relationship. However, there were many authors, such as V. Gupta, indicated that the quality of life and happiness affect performance of a person in the workplace [27]. If sexual disorder might affect performance of a person in working place and could trigger aggression in women, it makes sense that female teachers with sexual disorder could behave negatively against their own pupils.

\section{Conclusion}

Female teachers who experience sexual problems tend to decline in pedagogical performance. 


\section{Limitation and Future Study}

To be honest we have to admit that this research is still far from adequate. The main problem that we face in designing, conducting, and reporting the results of current is the difficulty of getting the appropriate literature on the relationship of sexual function with its impact on social and environmental issues. As long as the individual sexual problems, in both men and women, did not include the social, economic and environmental issues, then all the research on this field will not be too much benefit of mankind and society. For that reason we strongly encourage research that links the quality of sexual function problems with the performance and productivity of women be developed.

\section{Acknowledgement}

The authors are grateful for the research grant from Faculty of Medicine, University of Lampung.

\section{References}

[1] Meston C.M. and Bradford, A,"Sexual Dysfunction in Women,” Annu. Rev. Clin. Psychol., 3:233-56. 2007.

[2] van Klaveren, M., Tijde, K., Hughie-Williams, M. and Martin, N.R, “An overview of women's work and employment in Indonesia,” in Working Paper 10-91. May 2010. Amsterdam Institute for Advanced Labour Studies University of Amsterdam. CrossRef

[3] UNESCO. World education report 1998: Teachers and teaching in a changing world. Unesco Publishing, 1998, 178p.

[4] United Nation, "The World's Women 2010: Trends and Statistics," United Nation Publication Sales No. E.10.XVII.11. 2010.

[5] Hausmann, R., Tyson, L.D., Zahidi, S, The Global Gender Gap Report 2012. World Economic Forum collaborated with Faculty at Harvard University and the University of California. Berkeley.

[6] Thakur, K.S. and Kumar, S., "Mental Health as a Predictor of Emotional Competence of Prospective Teachers of Science in Himachal Pradesh,” MIER Journal of Educational Studies. Trends \& Practice. Vol. 3. No. 1 pp. 84-94. May 2013.

[7] Holeyannavar, P.G. and Itagi, S.K.,"Stress and Emotional Competence of Primary School Teachers," J Psychology, 3(1): 2938. 2012.

[8] Laumann, E.O., Nicolosi, A., Glasser, D.B., Paik, A., Gingell, C. Moreira, E. and Wang, T., "Sexual problems among women and men aged 40-80 y: prevalence and correlates identified in the Global Study of Sexual Attitudes and Behaviors,” International Journal of Impotence Research, 17. 39-57. 2005.

[9] Stronge. J., Qualities of effective teachers, Alexandria. VA Association for Supervision and Curriculum Development, 2002.

[10] Gorham, J. and Christophel, D.M., "Students' Perceptio of Teacher Behaviors As Motivating and Demotivating Factors in College
Classes,” Communication Quarterly. Vol. 40. No. 3. 239-252. Summer 1992.

[11] Fisher, D., Waldrip, B. and Brok, P.J, "Students' perceptions of primary teachers' interpersonal behaviour and of cultural dimensions in the classroom environment,” International Journal of Educational Research, 43(1/2). 25-38. 2005.

[12] Khine, M.S. and Atputhasamy, L., "Self-perceived and students' perceptio of teacher interaction in the classrooms," A paper presented at the Conference on Redesigning Pedagogy; Research. Policy. Practice. Singapore. 30 May to 1 June 2005.

[13] Keeley, J., Smith, D., \& Buskist, W., "The teacher behaviors checklist: Factor analysis of its utility for evaluating teaching," Teaching of Psychology, 33(2), 84-91. 2006.

[14] Rosen, R., Brown, C., Heiman, J., Leiblum, S., Ferguson, D. and D'agostino, R., "The Female Sexual Function Index (FSFI): A Multidimensional Self-Report Itrument for the Assessment of Female Sexual Function,” Journal of Sex \& Marital Therapy. 26: 191-208. 2000.

[15] Wiegel, M., Meston, C., and Rosen, R., The Female Sexual Function Index (FSFI): Cross-Validation and Development of Clinical Cutoff Scores. Journal of Sex \& Marital Therapy, 31: 120, 2005.

[16] Palacios,S., Castaño, R. and Graziottin, A., "Epidemiology of female sexual dysfunction,” Maturitas 63(2). 2009. Special issue on "Female sexual dysfunctions in the office: tools to meet the challenge", p. 119-123.

[17] Cayan, S., Akbay, E., Bozlu, M., Canpolat, B., Acar, D. and Ulusoy, E., "The prevalence of female sexual dysfunction and potential risk factors that may impair sexual function in Turkish women,” Urol Int. 2004.72(1):52-7.

[18] Thompson, R. J., Mata, J., Jaeggi, S. M., Buschkuehl, M., Jonides, J., \& Gotlib, I. H. (2012, June "The Everyday Emotional Experience of Adults With Major Depressive Disorder:Examining Emotional Instability, Inertia, and Reactivity”. Journal of Abnormal Psychology.

[19] Kunnskapssenteret, "Psychological, social and sexual consequences of female genital mutilation/cutting (FGM/C): a systematic review of quantitative studies," Report from Kunnskapssenteret (Norwegian Knowledge Centre for the Health Services) No.13-2010.Systematic review. pp.77.

[20] Marwick, C, "Survey Says Patients Expect Little Physician Help on Sex,” JAMA, 28.23: 2173-4. 1999.

[21] Blumberg, E.S, “The Lives and voices of highly sexual women," The Journal of Sex Research, 40.2: 146-157. 2003.

[22] Mah, K. and Binik, Y.M, "Female orgasmic disorders: A Clinical approach,” Urodinamica, 14:99-104. 2004.

[23] Fons, C.E, "Impact of sexual dysfunction on quality of life among anxiety disorder patients (2008)". Masters Theses and Doctoral Dissertations. (2008) Paper 189.

[24] Davison, S.L., Bell R.J., La China, M., Holden, S.L. and Davis, S.R, "The relationship between self-reported sexual satisfaction and general well-being in women," J Sex Med., 6(10):2690-7. Oct.2009.

[25] Dogan, T., Tugut, N. and Golbasi, Z, “The Relationship Between Sexual Quality of Life,Happiness, and Satisfaction with Life in Married Turkish Women,”.

[26] Edalati, A. and Redzuan, M, “A Review: Dominance, Marital Satisfaction and Female Aggression,” Journal of Social Sciences, 6 (2): 162-166. 2010.

[27] Gupta, V, “Importance of Being Happy at Work,” International Journal of Research and Development - A Management Review (IJRDMR), 1(1). 2012. 9-14. 